\section{Development of the Psychological Maltreatment Inventory}

\author{
Alison M. Boughn, Daniel A. DeCino
}

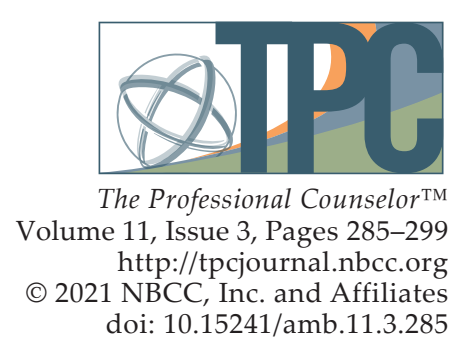

\$PG

Professional Counselor doi: 10.15241/amb.11.3.285

This article introduces the development and implementation of the Psychological Maltreatment Inventory (PMI) assessment with child respondents receiving services because of an open child abuse and/or neglect case in the Midwest $(N=166)$. Sixteen items were selected based on the literature, subject matter expert refinement, and readability assessments. Results indicate the PMI has high reliability $(\alpha=.91)$. There was no evidence the PMI total score was influenced by demographic characteristics. A positive relationship was discovered between PMI scores and general trauma symptom scores on the Trauma Symptom Checklist for Children Screening Form (TSCC-SF; $r=.78, p=.01$ ). Evidence from this study demonstrates the need to refine the PMI for continued use with children. Implications for future research include identification of psychological maltreatment in isolation, further testing and refinement of the PMI, and exploring the potential relationship between psychological maltreatment and suicidal ideation.

Keywords: psychological maltreatment, child abuse, neglect, assessment, trauma

In 2012, the Centers for Disease Control (CDC; 2012) reported that the total cost of child maltreatment (CM) in 2008, including psychological maltreatment (PM), was \$124 billion. Fang et al. (2012) estimated the lifetime burden of CM in 2008 was as high as $\$ 585$ billion. The CDC (2012) characterized CM as rivaling "other high profile public health problems" (para. 1). By 2015, the National Institutes of Health reported the total cost of CM, based on substantiated incidents, was reported to be $\$ 428$ billion, a 345\% increase in just 7 years; the true cost was predictably much higher (Peterson et al., 2018). Using the sensitivity analysis done by Fang et al. (2012), the lifetime burden of CM in 2015 may have been as high as $\$ 2$ trillion. If these trends continue unabated, the United States could expect a total cost for CM, including PM, of $\$ 5.1$ trillion by 2030 , with a total lifetime cost of $\$ 24$ trillion. More concerning, this increase would not account for any impact from the COVID-19 pandemic.

Mental health first responders and child protection professionals may encounter PM regularly in their careers (Klika \& Conte, 2017; U.S. Department of Health and Human Services [DHHS], 2018). PM experiences are defined as inappropriate emotional and psychological acts (e.g., excessive yelling, threatening language or behavior) and/or lack of appropriate acts (e.g., saying I love you) used by perpetrators of abuse and neglect to gain organizational control of their victims (American Professional Society on the Abuse of Children [APSAC], 2019; Klika \& Conte, 2017; Slep et al., 2015). Victims may experience negative societal perceptions (i.e., stigma), fear of retribution from caregivers or guardians, or misdiagnosis by professional helpers (Iwaniec, 2006; López et al., 2015). They often face adverse consequences that last their entire lifetime (Spinazzola et al., 2014; Tyrka et al., 2013; Vachon et al., 2015; van der Kolk, 2014; van Harmelen et al., 2010; Zimmerman \& Mercy, 2010). PM can be difficult to identify because it leaves no readily visible trace of injury (e.g., bruises, cuts, or broken bones), making it complicated to substantiate that a crime has occurred (Ahern et al., 2014; López et al., 2015). Retrospective data outlines evaluation processes for PM identification in adulthood; however, childhood PM lacks a single definition and remains difficult to assess (Tonmyr et al., 2011). These complexities in identifying

Alison M. Boughn, PhD, NCC, LIMHP (NE), LMHC (IA), LPC-MH (SD), ATR-BC, QMHP, TF-CBT, is an assistant professor and counseling department chair at Wayne State College. Daniel A. DeCino, PhD, NCC, LPC, is an assistant professor and Interim Program Coordinator at the University of South Dakota. Correspondence may be addressed to Alison M. Boughn, Wayne State College, 1111 Main Street, Wayne, NE 68787, albough1@wsc.edu. 
PM in children may prevent mental health professionals from intervening early, providing crucial care, and referring victims for psychological health services (Marshall, 2012; Spinazzola et al., 2014). The Psychological Maltreatment Inventory (PMI) is the first instrument of its kind to address these deficits.

\section{Child Psychological Maltreatment}

Although broadly conceptualized, child PM experiences are described as literal acts, events, or experiences that create current or future symptoms that can affect a victim without immediate physical evidence (López et al., 2015). Others have extended child PM to include continued patterns of severe events that impede a child from securing basic psychological needs and convey to the child that they are worthless, flawed, or unwanted (APSAC, 2019). Unfortunately, these broad concepts lack the specificity to guide legal and mental health interventions (Ahern et al., 2014). Furthermore, legal definitions of child PM vary from jurisdiction to jurisdiction and state to state (Spinazzola et al., 2014). The lack of consistent definitions and quantifiable measures of child PM may create barriers for prosecutors and other helping professionals within the legal system as well as a limited understanding of PM in evidence-based research (American Psychiatric Association [APA], 2013; APSAC, 2019; Klika \& Conte, 2017). These challenges are exacerbated by comorbidity with other forms of maltreatment.

\section{Co-Occurring Forms of Maltreatment}

According to DHHS (2018), child PM is rarely documented as occurring in isolation compared to other forms of maltreatment (i.e., physical abuse, sexual abuse, or neglect). Rather, researchers have found PM typically coexists with other forms of maltreatment (DHHS, 2018; Iwaniec, 2006; Marshall, 2012). Klika and Conte (2017) reported that perpetrators who use physical abuse, inappropriate language, and isolation facilitate conditions for PM to coexist with other forms of abuse. Van Harmelen et al. (2011) argued that neglectful acts constitute evidence of PM (e.g., seclusion; withholding medical attention; denying or limiting food, water, shelter, and other basic needs).

\section{Consequences of PM Experienced in Childhood}

Mills et al. (2013) and Greenfield and Marks (2010) noted PM experiences in early childhood might manifest in physical growth delays and require access to long-term care throughout a victim's lifetime. Children who have experienced PM may suffer from behaviors that delay or prevent meeting developmental milestones, achieving academic success in school, engaging in healthy peer relationships, maintaining physical health and well-being, forming appropriate sexual relationships as adults, and enjoying satisfying daily living experiences (Glaser, 2002; Maguire et al., 2015). Neurological and cognitive effects of PM in childhood impact children as they transition into adulthood, including abnormalities in the amygdala and hippocampus (Tyrka at al., 2013). Brown et al. (2019) found that adults who reported experiences of CM had higher rates of negative responses to everyday stress, a larger constellation of unproductive coping skills, and earlier mortality rates (Brown et al., 2019; Felitti et al., 1998). Furthermore, adults with childhood PM experiences reported higher rates of substance abuse than those compared to control groups (Felitti et al., 1998).

Trauma-Related Symptomology. Researchers speculate that children exposed to maltreatment and crises, especially those that come without warning, are at greater risk for developing a host of trauma-related symptoms (Spinazzola et al., 2014). Developmentally, children lack the ability to process and contextualize their lived experiences. Van Harmelen et al. (2010) discovered that adults who experienced child PM had decreased prefrontal cortex mass compared to those without evidence of PM. Similarly, Field et al. (2017) found those unable to process traumatic events produced higher levels of stress hormones (i.e., cortisol, epinephrine, norepinephrine); these hormones are produced from the hypothalamic-pituitary-adrenal (HPA) and sympathetic-adrenal-medullary (SAM) regions in 
the brain. Some researchers speculate that elevated levels of certain hormones and hyperactive regions within the brain signal the body's biological attempt to reduce the negative impact of PM through the fight-flight-freeze response (Porges, 2011; van der Kolk, 2014).

\section{Purpose of Present Study}

At the time of this research, there were few formal measures using child self-report to assess how children experience PM. We developed the PMI as an initial quantifiable measure of child PM for children and adolescents between the ages of 8 and 17, as modeled by Tonmyr and colleagues (2011). The PMI was developed in multiple stages, including 1 ) a review of the literature, 2) a content validity survey with subject matter experts (SMEs), 3$)$ a pilot study $(N=21)$, and 4$)$ a large sample study $(N=166)$. An additional instrument, the Trauma Symptom Checklist for Children Screening Form (TSCC-SF; Briere \& Wherry, 2016), was utilized in conjunction with the PMI to explore occurrences of general trauma symptoms among respondents. The following four research questions were investigated:

1. How do respondent demographics relate to PM?

2. What is the rate of PM experience with respondents who are presently involved in an open CM case?

3. What is the co-occurrence of PM among various forms of $\mathrm{CM}$ allegations?

4. What is the relationship between the frequency of reported PM experiences and the frequency of general trauma symptoms?

\section{Method}

\section{Study 1: PMI Item Development and Pilot}

Following the steps of scale construction (Heppner et al., 2016), the initial version of the PMI used current literature and definitions from facilities nationwide that provide care for children who have experienced maltreatment and who are engaged with court systems, mental health agencies, or social services. Our lead researcher, Alison M. Boughn, developed a list of 20 items using category identifications from Glaser (2002) and APSAC (2019). Items were also created using Slep et al.'s (2015) proposed inclusion language for the Diagnostic and Statistical Manual of Mental Disorders (DSM-5) diagnostic codes and codes from the International Classification of Diseases, 11th edition (ICD-11) definition criteria (APA, 2013). Both Boughn and Daniel A. DeCino, our other researcher, reviewed items for consistency with the research literature and removed four redundant items. The final 16 items were reevaluated for readability for future child respondents using a web-based, age range-appropriate readability checker (Readable, n.d.) and were then presented to local SMEs in a content validity survey to determine which would be considered essential for children to report as part of a child PM assessment.

\section{Expert Validation}

A multidisciplinary team (MDT) serving as SMEs completed an online content validity survey created by Boughn. The survey was distributed by a Child Advocacy Center (CAC) manager to the MDT. Boughn used the survey results to validate the PMI's item content relevance. Twenty respondents from the following professions completed the survey: mental health $(n=6)$, social services $(n=6)$, law enforcement $(n=3)$, and legal services $(n=5)$. The content validity ratio (CVR) was then calculated for the 16 proposed items.

Results. The content validity survey scale used a 3-point Likert-type scale: $0=$ not necessary; $1=$ useful, but not essential; and $2=$ essential. A minimum of 15 of the 20 SMEs ( $75 \%$ of the sample), or a CVR $\geq .5$, was required to deem an item essential (Lawshe, 1975). The significance level for each item's 
content validity was set at $\alpha=.05$ (Ayre \& Scally, 2014). After conducting Lawshe's (1975) CVR and applying the ratio correction developed by Ayre and Scally (2014), it was determined that eight items were essential: Item $2(\mathrm{CVR}=.7)$, Item $3(\mathrm{CVR}=.9)$, Item $4(\mathrm{CVR}=.6)$, Item $6(\mathrm{CVR}=.6)$, Item $7(\mathrm{CVR}=.8)$, Item $10(\mathrm{CVR}=.6)$, Item $15(\mathrm{CVR}=.5)$, and Item $16(\mathrm{CVR}=.6)$.

Upon further evaluation, and in an effort to ensure that the PMI items served the needs of interdisciplinary professionals, some items were rated essential for specific professions; these items still met the CVR requirements $(C V R=1)$ for the smaller within-group sample. These four items were unanimously endorsed by SMEs for a particular profession as essential: Item 5 (CVR Social Services = 1; CVR Law Enforcement =1), Item 11 (CVR Law Enforcement = 1), Item 13 (CVR Law Enforcement =1), and Item 14 (CVR Law Enforcement = 1).

Finally, an evaluation of the remaining four items was completed to explore if items were useful, but not essential. Using the minimum CVR $\geq .5$, it was determined that these items should remain on the PMI: Item $1(\mathrm{CVR}=.9)$, Item $8(\mathrm{CVR}=.8)$, Item $9(\mathrm{CVR}=.9)$, and Item $12(\mathrm{CVR}=.9)$. The use of Siegle's (2017) Reliability Calculator determined the Cronbach's $\alpha$ level for the PMI to be 0.83 , indicating adequate internal consistency. Additionally, a split-half (odd-even) correlation was completed with the Spearman-Brown adjustment of 0.88, indicating high reliability (Siegle, 2017).

\section{Pilot Summary}

The focus of the pilot study was to ensure effective implementation of the proposed research protocol following each respondent's appointment at the CAC research site. The pilot was implemented to ensure research procedures did not interfere with typical appointments and standard procedures at the CAC. Participation in the PMI pilot was voluntary and no compensation was provided for respondents.

Sample. The study used a purposeful sample of children at a local, nationally accredited CAC in the Midwest; both the child and the child's legal guardian agreed to participate. Because of the expected integration of PM with other forms of abuse, this population was selected to help create an understanding of how PM is experienced specifically with co-occurring cases of maltreatment. Respondents were children who (a) had an open CM case with social services and/or law enforcement, (b) were scheduled for an appointment at the CAC, and (c) were between the ages of 8 and 17.

Measures. The two measures implemented in this study were the developing PMI and the TSCC-SF. At the time of data collection, CAC staff implemented the TSCC-SF as a screening tool for referral services during CAC victim appointments. To ensure the research process did not interfere with chain-of-custody procedures, collected investigative testimony, or physical evidence that was obtained, the PMI was administered only after all normally scheduled CAC procedures were followed during appointments.

PMI. The current version of the PMI is a self-report measure that consists of 16 items on a 4-point Likert-type scale that mirrors the language of the TSCC-SF $(0=$ never to $3=$ almost all the time). Respondents typically needed 5 minutes complete the PMI. Sample items from the PMI included questions like: "How often have you been told or made to feel like you are not important or unlovable?" The full instrument is not provided for use in this publication to ensure the PMI is not misused, as refinement of the PMI is still in progress.

TSCC-SF. In addition to the PMI, Boughn gathered data from the TSCC-SF (Briere \& Wherry, 2016) because of its widespread use among clinicians to efficiently assess for sexual concerns, suicidal 
ideation frequency, and general trauma symptoms such as post-traumatic stress, depression, anger, disassociation, and anxiety (Wherry et al., 2013). The TSCC-SF measures a respondent's frequency of perceived experiences and has been successfully implemented with children as young as 8 years old (Briere, 1996). The 20 -item form uses a 4 -point Likert-type scale $(0=$ never to $3=$ almost all the time $)$ composed of general trauma and sexual concerns subscales. The TSCC-SF has demonstrated high internal consistency and alpha values in the good to excellent ranges; it also has high intercorrelations between sexual concerns and other general trauma scales (Wherry \& Dunlop, 2018).

Procedures. Respondents were recruited during their scheduled CAC appointment time. Each investigating agency (law enforcement or social services) scheduled a CAC appointment in accordance with an open maltreatment case. At the beginning of each respondent's appointment, Boughn provided them with an introduction and description of the study. This included the IRB approvals from the hospital and university, an explanation of the informed consent and protected health information (PHI) authorization, and assent forms. Respondents aged 12 and older were asked to read and review the informed consent document with their legal guardian; respondents aged from 8 to 11 were provided an additional assent document to read. Respondents were informed they could stop the study at any time. After each respondent and legal guardian consented, respondents proceeded with their CAC appointment.

Typical CAC appointments consisted of a forensic interview, at times a medical exam, and administration of the TSCC-SF to determine referral needs. After these steps were completed, Boughn administered the PMI to those who agreed to participate in this research study. Following the completion of the TSCC-SF, respondents were verbally reminded of the study and asked if they were still willing to participate by completing the PMI. Willing respondents completed the PMI; afterward, Boughn asked respondents if they were comfortable leaving the assessment room. In the event the respondent voiced additional concerns of maltreatment during the PMI administration, Boughn made a direct report to the respondent's investigator (i.e., law enforcement officer or social worker assigned to the respondent's case).

Boughn accessed each respondent's completed TSCC-SF from their electronic health record in accordance with the PHI authorization and consent after the respondent's appointment. Data completed on the TSCC-SF allowed Boughn to gather information related to sexual concerns, suicidal ideation, and trauma symptomology. Data gathered from the TSCC-SF were examined with each respondent's PMI responses.

Results. Respondents were 21 children (15 female, six male) with age ranges from 8 to 17 years with a median age of 12 years. Respondents described themselves as White (47.6\%), Biracial (14.2\%), Multiracial (14.2\%), American Indian/Alaskan Native (10.0\%), Black (10.0\%), and Hispanic/Latino $(5.0 \%)$. CM allegations for the respondents consisted of allegations of sexual abuse (86.0\%), physical abuse $(10.0 \%)$, and neglect $(5.0 \%)$.

Every respondent's responses were included in the analyses to ensure all maltreatment situations were considered. The reliability of the PMI observed in the pilot sample $(N=21)$ demonstrated high internal consistency with all 16 initial items $(\alpha=.88)$. The average total score on the PMI in the pilot was 13.29, with respondents' scores ranging from 1 to 30 . A Pearson correlation indicated total scores for the PMI and General Trauma Scale scores (reported on the TSCC-SF) were significantly correlated $(r=.517, p<.05)$. 


\section{Study 2: Full Testing of the PMI}

The next phase of research proceeded with the collection of a larger data sample $(N=166)$ to explore the item construct validity and internal reliability (Siyez et al., 2020). Study procedures, data collection, and data storage followed in the pilot study were also implemented with the larger sample. Boughn maintained tracking of respondents who did not want to participate in the study or were unable to because of cognitive functioning level, emergency situations, and emotional dysregulation concerns.

\section{Sample}

Based on a power analysis performed using the Raosoft (2004) sample size calculator, the large sample study required a minimum of 166 respondents for statistical significance (Ali, 2012; Heppner et al., 2016). The sample size was expected to account for a $10 \%$ margin of error and a $99 \%$ confidence level. The calculation of a 99\% confidence interval was used to ensure the number of respondents could effectively represent the population accessed within the CAC based on the data from the CM Report (DHHS, 2018). Large sample population data was gathered between September 2018 and May 2019.

\section{Measures}

The PMI and TSCC-SF were also employed in Study 2 because of their successful implementation in the pilot. Administration of the TSCC-SF ensured a normed and standardized measure could aid in providing context to the information gathered on the PMI. No changes were made to the PMI or TSCC-SF measures following the review of procedures and analyses in the pilot.

\section{Procedures}

Recruitment and data collection/analyses processes mirrored that of the pilot study. Voluntary respondents were recruited at the CAC during their scheduled appointments. Respondents completed an informed consent, child assent, PHI authorization form, TSCC-SF, and PMI. Following the completion of data collection, Boughn completed data entry in the electronic health record to de-identify and analyze the results.

\section{Results}

\section{Demographics}

All data were analyzed using Statistical Package for the Social Sciences version 24 (SPSS-24). Initial data evaluation consisted of exploration of descriptive statistics, including demographic and criteriabased information related to respondents' identities and case details. Respondents were between 8 to 17 years of age $(M=12.39)$ and primarily female $(73.5 \%, n=122)$, followed by male $(25.3 \%, n=42)$. Additionally, two respondents $(n=2)$ reported both male and female gender identities. Racial identities were marked by two categories: White $(59.6 \%, n=99)$ and Racially Diverse $(40.4 \%, n=67)$ respondents. The presenting maltreatment concerns and the child's relationship to the offender are outlined in Table 1 and Table 2, respectively.

\section{Reliability and Validity of the PMI}

The reliability of the PMI observed in its implementation in Study $2(N=166)$ showed even better internal consistency with all 16 initial items $(\alpha=.91)$ than observed in the pilot. Using the SpearmanBrown adjustment (Warner, 2013), split-half reliability was calculated, indicating high internal reliability (.92). Internal consistencies were calculated using gender identity and age demographic variables (see Table 3). 


\section{Table 1}

Child Maltreatment Allegation by Type $(\mathrm{N}=166)$

\begin{tabular}{lrccc}
\hline Allegation & \multicolumn{1}{c}{$f$} & $\operatorname{Rel} f$ & $\mathrm{cf}$ & $\%$ \\
\hline Sexual Abuse & 113 & 0.68 & 166 & 68.07 \\
Physical Abuse & 29 & 0.17 & 53 & 17.47 \\
Neglect & 14 & 0.08 & 24 & 8.43 \\
Multiple Allegations & 6 & 0.04 & 10 & 3.61 \\
Witness to Violence & 3 & 0.02 & 4 & 1.81 \\
Kidnapping & 1 & 0.01 & 1 & 0.60 \\
\hline
\end{tabular}

Note. Allegation type reported at initial appointment scheduling

\section{Table 2}

Identified Offender by Relationship to Victim ( $\mathrm{N}=166)$

\begin{tabular}{|c|c|c|c|c|}
\hline Offender Relationship & $f$ & $\operatorname{Rel} f$ & $c f$ & $\%$ \\
\hline Other Known Adult & 60 & 0.36 & 166 & 36.14 \\
\hline Parent & 48 & 0.29 & 106 & 28.92 \\
\hline Other Known Child ( $\leq$ age 15 years) & 15 & 0.09 & 58 & 9.04 \\
\hline Sibling-Child ( $\leq$ age 15 years) & 10 & 0.06 & 43 & 6.02 \\
\hline Unknown Adult & 9 & 0.05 & 33 & 5.42 \\
\hline Step-Parent & 8 & 0.05 & 24 & 4.82 \\
\hline Multiple Offenders & 6 & 0.04 & 16 & 3.61 \\
\hline Grandparent & 6 & 0.04 & 10 & 3.61 \\
\hline Sibling-Adult ( $\geq$ age 16 years) & 3 & 0.02 & 4 & 1.81 \\
\hline Unknown Child ( $\leq$ age 15 years) & 1 & 0.01 & 1 & 0.60 \\
\hline
\end{tabular}

Note. Respondent knew the offender $(n=156)$; Respondent did not know offender $(n=10)$

\section{Table 3}

Internal Consistency Coefficients ( $\alpha$ ) by Gender Identity and Age ( $\mathrm{N}=166)$

\begin{tabular}{lrrrr}
\hline \multicolumn{1}{c}{ Gender } & $n$ & $\alpha$ & \multicolumn{1}{c}{$M$} & \multicolumn{1}{c}{$S D$} \\
\hline Female & 122 & 0.90 & 13.2 & 9.1 \\
Male & 42 & 0.94 & 13.5 & 11.0 \\
Male-Female & 2 & 0.26 & 8.5 & 2.5 \\
\hline \multicolumn{1}{c}{ Age } & & & & \\
\hline $8-12$ & 83 & 0.92 & 12.75 & 10.06 \\
$13-17$ & 83 & 0.90 & 13.69 & 9.01 \\
\hline
\end{tabular}

Note. $S D=$ Standard Deviation; $M=$ Mean 


\section{Respondents' Demographic Characteristics and PM Experiences}

For Research Question (RQ) 1 and RQ2, descriptive data were used to generate frequencies and determine the impact of demographic characteristics on average PMI score. To explore this further in RQ1, one-way ANOVAs were completed for the variables of age, gender, racial identity, allegation type, and offender relationships. No significant correlations were found between demographic variables and the PMI items. On average, respondents reported a frequency score of $13.5(M=13.5$, $S D=9.5)$ on the PMI. Eight respondents (5\%) endorsed no frequency of PM while 95\% $(N=158)$ experienced PM.

\section{Co-Occurrence of PM With Other Forms of Maltreatment}

For RQ3, frequency and descriptive data were generated, revealing average age rates of PM reported by maltreatment type. Varying sample representations were discovered in each form of maltreatment (see Table 4). Clear evidence was found that PM co-occurs with each form of maltreatment type; however, how each form of maltreatment interacts with PM is currently unclear given the multiple dimensions of each maltreatment case including, but not limited to, severity, frequency, offender, and victim characteristics.

\section{Table 4}

Descriptive and Frequency Data for Co-Occurrence of PM ( $\mathrm{N}=166)$

\begin{tabular}{lrccc}
\hline Allegation & $n$ & $M$ & $S D$ & $95 \%$ CI \\
\hline Sexual Abuse & 113 & 13.04 & 9.01 & {$[11.37,14.72]$} \\
Physical Abuse & 29 & 12.45 & 10.53 & {$[8.44,16.45]$} \\
Neglect & 14 & 14.57 & 12.16 & {$[7.55,21.60]$} \\
Multiple Allegations & 5 & 17.40 & 8.88 & {$[6.38,28.42]$} \\
Witness to Violence & 3 & 7.67 & 5.03 & {$[-4.84,20.17]$} \\
Kidnapping & 1 & n/a & n/a & Missing \\
\hline
\end{tabular}

Note. $\mathrm{CI}=$ Confidence Interval; $S D=$ Standard Deviation; $M=$ Mean; $\mathrm{n} / \mathrm{a}=$ not applicable

\section{PM Frequency and General Trauma Symptoms}

For RQ4, Pearson's correlation was used to calculate frequency score relationships between the PMI and TSCC-SF. There was a statistically significant relationship between the PMI and total frequency of general trauma symptoms on the TSCC-SF $\left[r(164)=.78, p<.01, r^{2}=.61\right]$ (Sullivan \& Feinn, 2012). Cohen's $d$, calculated from the means for each item as well as the pooled standard deviation, indicated a small effect relationship $(d=.15)$ between general trauma and PMI frequencies (see Figure 1). 


\section{Figure 1}

Correlation Between PMI and TSCC-SF General Trauma Subscale

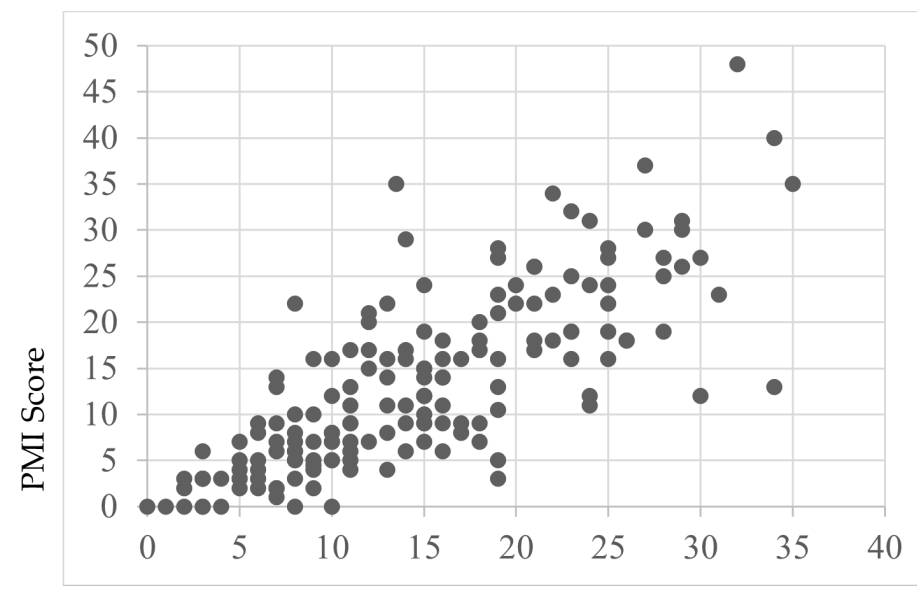

General Trauma (GT) Score

Note. Scores were endorsed by respondents' self-reports.

\section{Child Suicidal Ideation Reports and the PMI}

Following a review of the findings of Thompson et al. (2005) and Wherry et al. (2013) that children who reported experiencing $\mathrm{CM}$ also experienced suicidal ideation, Boughn performed an additional two-way ANOVA that examined the effect of suicidal ideation on the PMI total score. A significant relationship $-F(1,164)=49.52, p<.01, \eta^{2}=.23$ - between respondents' PMI scores and thoughts of suicide was found. Respondents who did not report thoughts of suicide $(59.0 \%, n=98)$ indicated lower rates of PM $(M=9.37, S D=7.97)$ compared to children who did report thoughts of suicide $(41.0 \%, n=68, M=18.77, S D=9.12)$. A preliminary review of this finding demonstrates the severity of PM's impact on child victims.

\section{Discussion}

This study was designed with the aim of developing a tool to support accurate identification of PM among children and adolescents. Findings from its first large-scale implementation provide a foundational view to the occurrence of PM in terms of demographic characteristics, comorbidity of PM with other forms of abuse, and the relationship between PM and trauma. The analyses yielded both expected and unexpected results based on the extant research.

\section{PM and Demographic Characteristics}

\section{Race}

There was no significant effect when exploring the data related to racial demographics and PM. The respondent sample closely reflected the geographical area's known racial demographics at the time of the study, reflecting a population approaching $80 \%$ White with residents of all other known races below $5 \%$ for each racial group (U.S. Census Bureau, 2020). Although researchers (Dakil et al., 2011) anticipated children identifying as racial minorities would be included in the representation of $\mathrm{CM}$ reports, evidence 
from this study potentially reveals a greater than expected gap in reporting for minority-race populations (Bernard \& Harris, 2018; Font \& Maguire-Jack, 2015). This suggests that there may be additional, unidentified barriers influencing the reporting of maltreatment among minority-race populations.

\section{Gender}

A lack of gender identity representation was evident in the data, consistent with prior research (Sivagurunathan et al., 2019). Respondents who self-identified with both male and female gender identities $(1.2 \%)$ and as male $(25.3 \%)$ were represented less frequently compared to female respondents $(73.5 \%)$. This is not inherently a limitation of this study, as research shows that just $10 \%$ of males in the United States report their sexual abuse (Sivagurunathan et al., 2019). People who identify as male may face harmful cultural messages that enhance negative stigma for victims of abuse, causing increased feelings of weakness or vulnerability (Alaggia \& Mishna, 2014). This finding may support claims that male trauma survivors feel stigmatized and report their experiences less frequently (Easton, 2012).

Additionally, children who identify outside traditional gender binary norms and definitions need more access to inclusive representation on screening assessments. Assessments like the TSCC-SF may be using antiquated gender- or biological sex-normed checkboxes, which leave certain groups underrepresented in research studies (Neukrug \& Fawcett, 2015). These practices may present inaccurate findings, inadvertently reinforce discriminatory expectations, and generate inaccurate referrals. Non-binary youth encounter barriers that may compound their ability to effectively access supports in their daily life related to coming out, social violence, lack of peer and/or adult acceptance, discrimination, isolation, higher rates of suicide, and lack of representation in mainstream society (Bialer \& McIntosh, 2016; Zimman, 2009). In this study, representation of non-binary respondents, specifically those who reported both male and female gender identities, was reported; this warrants further exploration to assess barriers among non-binary gender youth and their experiences with child PM (Bos et al., 2019).

\section{Offender Relationships}

Frequency data for a child's relationship with the offender were not found to be significant either for known offenders $(M=13.35)$ or unknown offenders $(M=11.2)$. In this study, $94 \%$ of the respondents already knew their offender $(n=156)$. This finding is consistent with previous research that has found that although child abduction and stranger danger are real phenomena, children are more likely to experience CM as a result of relationships with familiar individuals (Walsh \& Brandon, 2011).

\section{Co-Occurrence of PM With Other Abuse}

Only eight respondents (5\%) endorsed no frequency of PM; the average total PM frequency rate for respondents in this study was 13.5 out of a possible 48 , indicating extreme severity. In this study, we found evidence that PM is a co-occurring experience for children with open maltreatment cases, yet clinicians still lack formal, valid assessments to determine PM alone. Our findings support the National Children's Alliance's (NCA; 2016) call for clinicians to follow practice guidelines in accordance with state and national guidelines as they relate to mandatory reporting of $\mathrm{CM}$ concerns and determination of whether PM plus other forms of maltreatment may be present for child victims seeking services.

\section{Comorbidity of PM and Trauma}

PM-related experiences on the PMI and general trauma symptoms from the TSCC-SF warrant discussion. The PMI illustrated a significant relationship with the TSCC-SF general trauma subscale (Briere \& Wherry, 2016). More than half (61\%) of the variance on the PMI was connected to general 
trauma symptoms, suggesting that higher rates of PM experiences may increase trauma-related symptoms. For example, previous researchers have found adverse childhood experiences and signs of trauma-related symptoms lead to serious mental health diagnoses, early mortality, and/or significant biological health risks in children (Tyrka et al., 2013; Vachon et al., 2015; Zimmerman \& Mercy, 2010). Further exploration to determine if and how PM influences other trauma-related symptoms in children throughout their life span would expand upon the results of this study.

\section{Suicidal Ideation}

Finally, our data revealed a significant effect between respondent endorsement of suicidal ideation and PMI total scores. PM experiences accounted for $23 \%$ of the variance for children who reported thoughts of suicide $(41 \%, n=68)$ compared to those who did not report thoughts of suicide $(59 \%, n=98)$. This finding is consistent with prior research exploring children's experiences with maltreatment and suicidal thoughts (Thompson et al., 2005; Wherry et al., 2013).

\section{Limitations}

This study has several limitations. First, by developing the PMI using national definitions, some regional and localized nuances were not considered. Second, data collected for this study were from a single Midwest CAC; thus, the data are limited in geographic generalizability. Third, the majority of respondents were White, and a more diverse sample would have been more representative of the region in which data were collected. Fourth, $99 \%$ of respondents identified as either male or female and may reflect an underrepresentation of non-binary or gender fluid youth in the results of this study. Fifth, this study relied heavily on quantitative data, which limited the ability to analyze each individual's experiences with PM as they might describe from their unique perspectives.

\section{Implications for Research and Practice}

The results of this study provide several areas for future research. While the PMI demonstrated good internal consistency across all items $(\alpha=.91)$, more research with diverse populations across the United States is needed. Research from other geographical locations may demonstrate how reporting patterns for PM interact with ethnicity, culture, and elements of social expectations (Spinazzola et al., 2014).

The initial results of this study indicate the PMI may be a useful tool for children to report PM experiences in CAC settings; however, future research at other CACs and similar treatment facilities is needed to determine the PMI's true utility and scalability. Future analysis (i.e., exploratory factor analysis and confirmatory factor analysis) of the PMI may also identify factors and help refine the instrument.

More research with the PMI can expand researchers' knowledge of PM and services needed to help children. Working with other CACs, child protection professionals, and the NCA may help bridge current gaps in interdisciplinary assessment and care and establish a stable and comprehensive understanding of PM (López et al., 2015). Furthermore, understanding how CACs are equipped to identify and handle PM cases may provide useful insights to help improve services for children in need. Although some CACs may have a variety of professionals working in specific roles, some CACs may be understaffed, causing staff to take on multiple and overlapping roles. It is important to understand if and how different combinations of trained professionals influence children reporting PM (Hart \& Glaser, 2011; NCA, 2016).

More research with the PMI is needed for refinement and to ensure the instrument is not misused. Releasing the PMI at this stage to clinicians and researchers without a fully developed assessment manual may lead to inappropriate or ineffective administration of the PMI and potentially unethical 
practice that could place children at risk. Future research and refinement of the PMI may provide clinicians and researchers a reliable and valid tool that is grounded in consistent theory and practice.

\section{Conclusion}

The PMI was developed to assess child PM and offers researchers and clinicians useful findings. In supporting research (Arslan, 2017; Bernstein et al., 2013; Raparia et al., 2016), child PM is a serious and often harmful combination of experiences that requires professional intervention (APSAC, 2019). For children reporting PM experiences, the PMI may help mental health and other care providers determine which services are needed. Findings from this study suggest differences in demographic variables are minimal for PM. Overall PMI scores were correlated to the general trauma subscale on the TSCC-SF, and the PMI revealed higher rates of PM for children experiencing suicidal ideation. The findings are the beginning of a measure designed to illustrate the depth and frequency of PM for children. With the PMI, early PM intervention becomes possible for a once invisible form of maltreatment.

\section{Conflict of Interest and Funding Disclosure}

Data collected and content shared in this study

were part of a dissertation study, which was awarded the 2020 Dissertation Excellence Award by the National Board for Certified Counselors. The Psychological Maltreatment Inventory (PMI) items were not released in this publication to protect victims of child maltreatment and to ensure future publications can address comprehensive revisions made to the PMI.

\section{References}

Ahern, E. C., Hershkowitz, I., Lamb, M. E., Blasbalg, U., \& Winstanley, A. (2014). Support and reluctance in the pre-substantive phase of alleged child abuse victim investigative interviews: Revised versus standard NICHD protocols. Behavioral Sciences $\mathcal{E}$ the Law, 32(6), 762-774. https://doi.org/10.1002/bsl.2149

Alaggia, R., \& Mishna, F. (2014). Self psychology and male child sexual abuse: Healing relational betrayal. Clinical Social Work Journal, 42(1), 41-48. https://doi.org/10.1007/s10615-013-0453-2

Ali, S. A. (2012). Sample size calculation and sampling techniques. Journal of the Pakistan Medical Association, 62(6), 624-626. https://jpma.org.pk/PdfDownload/3482

American Professional Society on the Abuse of Children. (2019). APSAC practice guidelines: The investigation and determination of suspected psychological maltreatment of children and adolescents. https://bit.ly/3jI7AhJ

American Psychiatric Association. (2013). Diagnostic and statistical manual of mental disorders (5th ed.).

Arslan, G. (2017). Psychological maltreatment, coping strategies, and mental health problems: A brief and effective measure of psychological maltreatment in adolescents. Child Abuse $\mathcal{E}$ Neglect, 68, 96-106. https://doi.org/10.1016/j.chiabu.2017.03.023

Ayre, C., \& Scally, A. J. (2014). Critical values for Lawshe's content validity ratio: Revisiting the original methods of calculation. Measurement and Evaluation in Counseling and Development, 47(1), 79-86. https://doi.org/10.1177\%2F0748175613513808

Bernard, C., \& Harris, P. (2018). Serious case reviews: The lived experience of Black children. Child E Family Social Work, 24(2), 256-263. https://doi.org/10.1111/cfs.12610 
Bernstein, R. E., Measelle, J. R., Laurent, H. K., Musser, E. D., \& Ablow, J. C. (2013). Sticks and stones may break my bones but words relate to adult physiology? Child abuse experience and women's sympathetic nervous system response while self-reporting trauma. Journal of Aggression, Maltreatment $\mathcal{E}$ Trauma, 22(10), 1117-1136. https://doi.org/10.1080/10926771.2013.850138

Bialer, P. A., \& McIntosh, C. A. (2016). Discrimination, stigma, and hate: The impact on the mental health and well-being of LGBT people. Journal of Gay \& Lesbian Mental Health, 20(4), 297-298. https://doi.org/10.1080/19359705.2016.1211887

Bos, H., de Haas, S., \& Kuyper, L. (2019). Lesbian, gay, and bisexual adults: Childhood gender nonconformity, childhood trauma, and sexual victimization. Journal of Interpersonal Violence, 34(3), 496-515. https://doi.org/10.1177\%2F0886260516641285

Briere, J. (1996). Trauma Symptom Checklist for Children (TSCC), professional manual. Psychological Assessment Resources.

Briere, J., \& Wherry, J. (2016). Development and validation of the TSCC Screening Form (TSCC-SF) and TSCYC Screening Form (TSCYC-SF). Psychological Assessment Resources.

Brown, S. M., Bender, K., Orsi, R., McCrae, J. S., Phillips, J. D., \& Rienks, S. (2019). Adverse childhood experiences and their relationship to complex health profiles among child welfare-involved children: A classification and regression tree analysis. Health Services Research, 54(4), 902-911. https://doi.org/10.1111/1475-6773.13166

Centers for Disease Control. (2012). Child abuse and neglect cost the United States $\$ 124$ billion [Press release]. https://bit.ly/3jYbpAF

Dakil, S. R., Cox, M., Lin, H., \& Flores, G. (2011). Racial and ethnic disparities in physical abuse reporting and Child Protective Services interventions in the United States. Journal of the National Medical Association, 103(9-10), 926-931. https://doi.org/10.1016/S0027-9684(15)30449-1

Easton, S. D. (2012). Disclosure of child sexual abuse among adult male survivors. Clinical Social Work Journal, 41, 344-355. https://doi.org/10.1007/s10615-012-0420-3

Fang, X., Brown, D. S., Florence, C. S., \& Mercy, J. A. (2012). The economic burden of child maltreatment in the United States and implications for prevention. Child Abuse \& Neglect, 36(2), 156-165. https://doi.org/10.1016/j.chiabu.2011.10.006

Felitti, V. J., Anda, R. F., Nordenberg, D., Williamson, D. F., Spitz, A. M., Edwards, V., Koss, M. P., \& Marks, J. S. (1998). Relationship of childhood abuse and household dysfunction to many of the leading causes of death in adults: The Adverse Childhood Experiences (ACE) study. American Journal of Preventive Medicine, 14(4), 245-258. https://doi.org/10.1016/S0749-3797(98)00017-8

Field, T. A., Jones, L. K., \& Russell-Chapin, L. A. (Eds.). (2017). Neurocounseling: Brain-based clinical approaches. American Counseling Association.

Font, S. A., \& Maguire-Jack, K. (2015). Decision-making in Child Protective Services: Influences at multiple levels of the social ecology. Child Abuse E Neglect, 47, 70-82. https://doi.org/10.1016/j.chiabu.2015.02.005

Glaser, D. (2002). Emotional abuse and neglect (psychological maltreatment): A conceptual framework. Child Abuse E Neglect, 26(6-7), 697-714. https://doi.org/10.1016/S0145-2134(02)00342-3

Greenfield, E. A., \& Marks, N. F. (2010). Identifying experiences of physical and psychological violence in childhood that jeopardize mental health in adulthood. Child Abuse \& Neglect, 34(3), 161-171. https://doi.org/10.1016/j.chiabu.2009.08.012

Hart, S. N., \& Glaser, D. (2011). Psychological maltreatment - Maltreatment of the mind: A catalyst for advancing child protection toward proactive primary prevention and promotion of personal well-being. Child Abuse \& Neglect, 35(10), 758-766. https://doi.org/10.1016/j.chiabu.2011.06.002

Heppner, P. P., Wampold, B. E., Owen, J., Thompson, M. N., \& Wang, K. T. (2016). Research design in counseling (4th ed.). Cengage.

Iwaniec, D. (2006). The emotionally abused and neglected child: Identification, assessment and intervention: A practice handbook (2nd ed.). Wiley.

Klika, J. B., \& Conte, J. R. (Eds.). (2017). The APSAC handbook on child maltreatment (4th ed.). SAGE.

Lawshe, C. H. (1975). A quantitative approach to content validity. Personnel Psychology, 28(4), 563-575. https://doi.org/10.1111/j.1744-6570.1975.tb01393.x

López, M., Fluke, J. D., Benbenishty, R., \& Knorth, E. J. (2015). Commentary on decision-making and judgments in child maltreatment prevention and response: An overview. Child Abuse E Neglect, 49, 1-11. https://doi.org/10.1016/j.chiabu.2015.08.013 
Maguire, S. A., Williams, B., Naughton, A. M., Cowley, L. E., Tempest, V., Mann, M. K., Teague, M., \& Kemp, A. M. (2015). A systematic review of the emotional, behavioural and cognitive features exhibited by school-aged children experiencing neglect or emotional abuse. Child: Care, Health and Development, 41(5), 641-653. https://doi.org/10.1111/cch.12227

Marshall, N. A. (2012). A clinician's guide to recognizing and reporting parental psychological maltreatment of children. Professional Psychology: Research and Practice, 43(2), 73-79. https://doi.org/10.1037/a0026677

Mills, R., Scott, J., Alati, R., O'Callaghan, M., Najman, J. M., \& Strathearn, L. (2013). Child maltreatment and adolescent mental health problems in a large birth cohort. Child Abuse E Neglect, 37(5), 292-302. https://doi.org/10.1016/j.chiabu.2012.11.008

National Children's Alliance. (2016). Putting standards into practice: A guide to implementing the 2017 standards for accredited members (revised 2016). http://www.nationalchildrensalliance.org/wp-content/ uploads/2015/06/NCA2017-StandardsIntoPractice-web.pdf

Neukrug, E. S., \& Fawcett, R. C. (2015). The essentials of testing and assessment: A practical guide for counselors, social workers, and psychologies, enhanced (3rd ed.). Cengage.

Peterson, C., Florence, C., \& Klevens, J. (2018). The economic burden of child maltreatment in the United States, 2015. Child Abuse \& Neglect, 86, 178-183. https://doi.org/10.1016/j.chiabu.2018.09.018

Porges, S. W. (2011). The polyvagal theory: Neurophysiological foundations of emotions, attachment, communication, and self-regulation. W. W. Norton.

Raosoft. (2004). Sample size calculator. http://www.raosoft.com/samplesize.html

Raparia, E., Coplan, J. D., Abdallah, C. G., Hof, P. R., Mao, X., Mathew, S. J., \& Shungu, D. C. (2016). Impact of childhood emotional abuse on neocortical neurometabolites and complex emotional processing in patients with generalized anxiety disorder. Journal of Affective Disorders, 190, 414-423.

https://doi.org/10.1016/j.jad.2015.09.019

Readable. (n.d.). https://readable.com

Siegle, R. (2017). Educational research basics: Excel spreadsheet to calculate instrument reliability estimates. https://res earchbasics.education.uconn.edu/excel-spreadsheet-to-calculate-instrument-reliability-estimates

Sivagurunathan, M., Orchard, T., \& Evans, M. (2019). Barriers to utilization of mental health services amongst male child sexual abuse survivors: Service providers' perspective. Journal of Child Sexual Abuse, 28(7), 819-839. https://doi.org/10.1080/10538712.2019.1610823

Siyez, D. M., Esen, E., Seymenler, S., \& Öztürk, B. (2020). Development of wellness scale for emerging adults: Validity and reliability study. Current Psychology. https://doi.org/10.1007/s12144-020-00672-w

Slep, A. M. S., Heyman, R. E., \& Foran, H. M. (2015). Child maltreatment in DSM-5 and ICD-11. Family Process, 54(1), 17-32. https://doi.org/10.1111/famp.12131

Spinazzola, J., Hodgdon, H., Liang, L.-J., Ford, J. D., Layne, C. M., Pynoos, R., Briggs, E. C., Stolbach, B., \& Kisiel, C. (2014). Unseen wounds: The contribution of psychological maltreatment to child and adolescent mental health and risk outcomes. Psychological Trauma: Theory, Research, Practice, and Policy, 6(Suppl 1), S18-S28. https://doi.org/10.1037/a0037766

Sullivan, G. M., \& Feinn, R. (2012). Using effect size-or why the $p$ value is not enough. Journal of Graduate Medical Education, 4(3), 279-282. https://doi.org/10.4300/JGME-D-12-00156.1

Thompson, R., Briggs, E., English, D. J., Dubowitz, H., Lee, L.-C., Brody, K., Everson, M. D., \& Hunter, W. M. (2005). Suicidal ideation among 8-year-olds who are maltreated and at risk: Findings from the LONGSCAN studies. Child Maltreatment, 10(1), 26-36. https://doi.org/10.1177\%2F1077559504271271

Tonmyr, L., Draca, J., Crain, J., \& MacMillian, H. L. (2011). Measurement of emotional/psychological child maltreatment: A review. Child Abuse \& Neglect, 35(10), 767-782. https://doi.org/10.1016/j.chiabu.2011.04.011

Tyrka, A. R., Burgers, D. E., Philip, N. S., Price, L. H., \& Carpenter, L. L. (2013). The neurobiological correlates of childhood adversity and implications for treatment. Acta Psychiatrica Scandinavica, 128(6), 434-447. https://doi.org/10.1111/acps.12143

U.S. Census Bureau. (2020). Quick facts. https://www.census.gov

U.S. Department of Health \& Human Services. (2018). Child maltreatment 2016 (27th ed.). https://www.acf.hhs. gov/sites/default/files/documents/cb/cm2016.pdf 
Vachon, D. D., Krueger, R. F., Rogosch, F. A., \& Cicchetti, D. (2015). Assessment of the harmful psychiatric and behavioral effects of different forms of child maltreatment. JAMA Psychiatry, 72(11), 1135-1142. https://doi.org/10.1001/jamapsychiatry.2015.1792

van der Kolk, B. (2014). The body keeps the score: Brain, mind, and body in the healing of trauma. Penguin Books.

van Harmelen, A.-L., Elzinga, B. M., Kievit, R. A., \& Spinhoven, P. (2011). Intrusions of autobiographical memories in individuals reporting childhood emotional maltreatment. European Journal of Psychotraumatology, 2(1), 7336. https://doi.org/10.3402/ejpt.v2i0.7336

van Harmelen, A.-L., van Tol, M.-J., van der Wee, N. J. A., Veltman, D. J., Aleman, A., Spinhoven, P., van Buchem, M. A., Zitman, F. G., Penninx, B. W. J. H., \& Elzinga, B. M. (2010). Reduced medial prefrontal cortex volume in adults reporting childhood emotional maltreatment. Biological Psychiatry, 68(9), 832838. https://doi.org/10.1016/j.biopsych.2010.06.011

Walsh, K., \& Brandon, L. (2011). Their children's first educators: Parents' views about child sexual abuse prevention education. Journal of Child and Family Studies, 21, 734-746. https://doi.org/10.1007/s10826-011-9526-4

Warner, R. M. (2013). Applied statistics: From bivariate through multivariate techniques (2nd ed.). SAGE.

Wherry, J. N., Baldwin, S., Junco, K., \& Floyd, B. (2013). Suicidal thoughts/behaviors in sexually abused children. Journal of Child Sexual Abuse, 22(5), 534-551. https://doi.org/10.1080/10538712.2013.800938

Wherry, J. N., \& Dunlop, C. E. (2018). TSCC and TSCYC screening forms in a clinical sample: Reliability, validity, and creating local clinical norms. Child Maltreatment, 23(1), 74-84. https://doi.org/10.1177\%2F1077559517725207

Zimman, L. (2009). 'The other kind of coming out': Transgender people and the coming out narrative genre. Gender and Language, 3(1), 53-80. https://doi.org/10.1558/genl.v3i1.53

Zimmerman, F., \& Mercy, J. (2010). A better start: Child maltreatment prevention as a public health priority. Zero to Three, 30(5), 4-10. 